\title{
FROM BEALE NUMBER TO POLE PLACEMENT DESIGN OF A FREE PISTON STIRLING ENGINE
}

\begin{abstract}
In this paper, pole placement-based design and analysis of a free piston Stirling engine (FPSE) is presented and compared to the well-defined Beale number design technique. First, dynamic and thermodynamic equations governing the engine system are extracted. Then, linear dynamics of the free piston Stirling engine are studied using dynamic systems theory tools such as root locus. Accordingly, the effects of variations of design parameters such as mass of pistons, stiffness of springs, and frictional damping on the locations of dominant closed-loop poles are investigated. The design procedure is thus conducted to place the dominant poles of the dynamic system at desired locations on the s-plane so that the unstable dynamics, which is the required criterion for energy generation, is achieved. Next, the closed-loop poles are selected based on a desired frequency so that a periodical system is found. Consequently, the design parameters, including mass and spring stiffness for both power and displacer pistons, are obtained. Finally, the engine power is calculated through the proposed control-based analysis and the result is compared to those of the experimental work and the Beale number approach. The outcomes of this work clearly reveal the effectiveness of the control-based design technique of FPSEs compared to the well-known approaches such as Beale number.
\end{abstract}

\section{Introduction}

The Stirling engine is a heat engine that operates based on the cyclic compression and expansion of a gaseous working fluid at different temperature levels. The Stirling engine has a high efficiency and relatively quiet operation compared to other types of the heat engines [1,2]. Moreover, it can use various heat sources and thus, is compatible with alternative and renewable energies [1]. The Stirling engine was invented by Robert Stirling in 1816. Stirling engines can be classified as kinematic and dynamic engines. The free piston Stirling engines

\footnotetext{
${ }^{1}$ Department of Mechanical and Aerospace Engineering, Shiraz University of Technology, Shiraz, Iran.Emails:s.zare@sutech.ac.ir,tavakolpour@sutech.ac.ir,omidvar@sutech.ac.ir
} 
(FPSEs) are known as a type of dynamic Stirling engines. The first FPSE was designed by Beale in 1964 [1]. Such a Stirling engine has no kinematic mechanisms coupling the reciprocating elements to each other or to a common rotating shaft. Instead, the elements move entirely in response to the spring forces upon them.

Investigations on the performance of the Stirling engines are known to be a critical issue in designing the Stirling converter. So far, various empirical and analytical theories have been devised by researchers to predict the performance of the Stirling engines [1]. The first theoretical approach towards the estimation of the engine power, known as Schmidt's theory [1, 3-5], was introduced for the kinematic type of the Stirling engines. Tavakolpour-Saleh et al. [6] have investigated the performance of a kinematic low-temperature Stirling engine with two cylinders connected to one crankshaft. They have presented a novel theory for the prediction of real gas temperature to calculate the engine's power. Cheng et al. [7] utilized a non-ideal adiabatic theory to predict the performance of a $\beta$-type $300 \mathrm{~W}$ self-made kinematic Stirling engine with an error of 12-20\%. The effect of the regenerator wire mesh number on the shaft power was tested, and an optimal mesh number was recommended. Tlili and Musmar [8] studied the effect of the geometrical and physical parameters on the performance of a Stirling engine containing Ross Yoke mechanism. They presented thermodynamic optimization of the Ross Yoke engine based on a numerical model integrating the internal and external irreversibility. Hachem et al. [9] extended the Urieli quasi-steady model by adding thermal and mechanical losses to analyze the effect of heat exchanger efficiency on the performance of a gamma-type Stirling engine. The obtained results demonstrated that, for a high initial filling pressure, the brake power is more sensitive to the rotational speed as well as the hot end temperature.

Obviously, Schmidt's theory was not enough to correctly investigate the performance of the dynamic type of the Stirling engines. Consequently, many researchers have proposed different mathematical models to predict the performance of such engines, each of which possesses particular advantages and drawbacks. Beale [10-12] carried out the first dynamic analysis of the FPSE. Walker and Senft [5] presented another preliminary analysis on FPSEs considering the assumptions of Schmidt's theory. However, the fundamental of the Schmidt's theory was based on the kinematic engines. Consequently, different researchers strived to present appropriate analytical approaches to model such dynamic engines.

Formosa [13] developed a global semi-analytical model for the preliminary design of a free piston Stirling engine. He estimated the performance of a FPSE by coupling thermodynamic and dynamic equations. He considered the regenerator efficiency, the performance of heat exchangers, and the heat losses in the optimization process of FPSE.

Zare and Tavakolpour-Saleh [14] proposed a novel frequency-based design approach of the free piston Stirling engines using a genetic algorithm (GA). In this work, the optimum values of design parameters, i.e., mass and spring stiffness 
of the power and displacer pistons and the cross-sectional area of the displacer rod were obtained using GA. They showed that the proposed design technique could estimate the operating frequency and the generated power of FPSEs with an acceptable accuracy.

Karabulut [15] presented a dynamic model for the free piston Stirling engines based on open and closed thermodynamic cycles. Their results revealed that the engine possessing closed thermodynamic cycle was stable within a smaller range of hot end temperature and damping coefficients.

Kwankaomeng et al. [16] designed, constructed, and analysed a FPSE engine. In this research, the generated power and efficiency of the engine corresponding to different frequencies were obtained. The experimental results of the FPSE clearly demonstrated that a maximum output power of $0.68 \mathrm{~W}$ was found at $6.4 \mathrm{~Hz}$ engine speed using a $10 \mathrm{~W}$ heat source. Kwankaomeng et al. [17] presented a revolutionary approach to predict the performance of a FPSE with a swept volume of $23 \mathrm{~cm}^{3}$. The developed prototype engine was equipped with an air cooling system and an alcohol burner was used to heat the engine. The testing results showed that the engine achieved an output power of about $0.10 \mathrm{~W}$ at $730 \mathrm{RPM}$ considering a 10.45 $\mathrm{W}$ heat source. However, this research was just a preliminary work to determine the performance of the engine. Vichaidit et al. [18] designed, manufactured, and tested a free piston Stirling engine with a swept volume of about $46.65 \mathrm{~cm}^{3}$. The presented prototype was able to operate within a temperature range of $100^{\circ} \mathrm{C}$ to $280^{\circ} \mathrm{C}$, and at atmospheric pressure. Next, frequency-stroke characteristics of the engine were measured and reported. The experimental results showed that a maximum output power of $4.69 \mathrm{~W}$ was achievable at hot and cold temperatures of $163^{\circ} \mathrm{C}$ and $40^{\circ} \mathrm{C}$ respectively. Rogdakis et al. [19] presented a dynamic model for FPSEs possessing three degrees of freedom. The obtained model was thus simulated by linearizing the obtained equations around an equilibrium state. Boucher et al. [20] carried out an analysis on a free piston Stirling engine possessing a power piston and two displacers and then, obtained optimum values of design parameters for $1 \mathrm{~kW}$ output power. Tavakolpour-Saleh et al. [21] applied a perturbation technique to the analysis of a FPSE possessing nonlinear springs. The method of multiple-scale was used in this investigation to achieve the final solutions of the governing nonlinear differential equations.

In the present article, control-based design of a free piston Stirling engine is considered as an alternative to the well-defined Beale number approach. Accordingly, the root locus approach incorporating dynamic and thermodynamic equations are utilized to study the dynamic behaviour of the engine system. First, the effects of variations of design parameters (i.e. the mass of pistons and stiffness of springs) on the locations of the dominant eigenvalues (poles) of the system and the engine performance are investigated. Next, based on a desired frequency, locations of the dominant and non-dominant poles are selected such that engine's marginal stability is founded. Consequently, the engine design parameters such as the mass of pistons and stiffness of springs are obtained. Finally, in order to validate the presented 
design technique, the estimated output powers of the engine corresponding to different operating frequencies are compared to experimental data and the predicted values by Beale number approach.

\section{Fundamentals of the free piston Stirling engines}

A schematic representation of a FPSE is given in Fig. 1. The internal volume of the FPSE can be divided into compression and expansion spaces. The mentioned spaces are connected together through a duct incorporating a regenerator. Although the regenerator is a key element in the FPSE, however, it can be neglected at the expense of a lower output power and efficiency. It is made of a porous metallic material, which absorbs and rejects heat periodically during the thermodynamic cycle. In addition, the regenerator serves to provide a more realistic isothermal process in the thermodynamic cycle. The ideal Stirling cycle includes two isothermal and two isochoric processes as shown in Fig. 2 [1]. According to this figure, the Stirling cycle contains four states, i.e., heating, expansion, cooling, and compression. A short explanation of each thermodynamic state is given in Fig. 3.

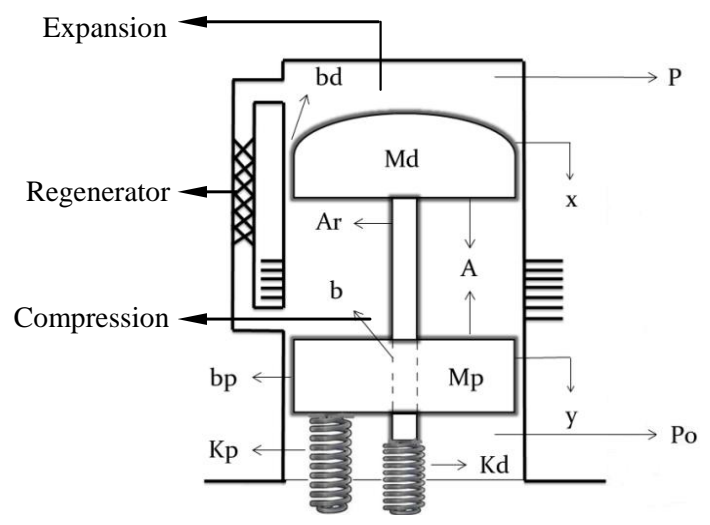

Fig. 1. Schematic representation of a FPSE

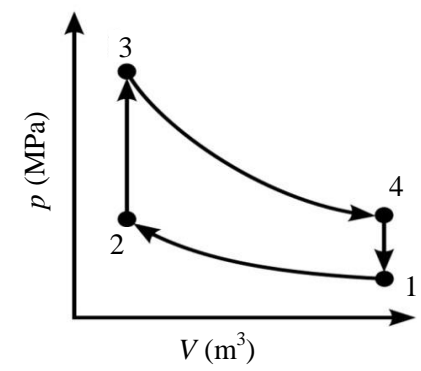

Fig. 2. Ideal Stirling cycle 


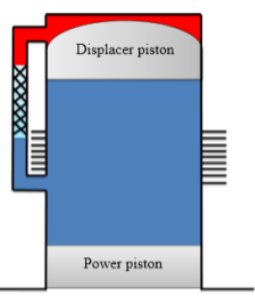

1

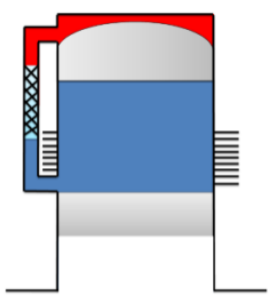

2

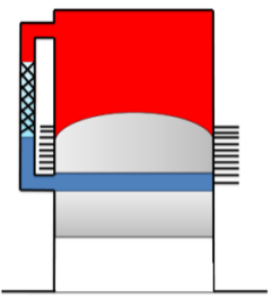

3

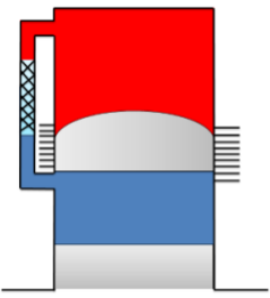

4

Fig. 3. Working principle of a free piston Stirling engine

\section{Linearized model of FPSE}

In this section, the thermodynamic and dynamic equations are used to investigate the behaviour of the FPSE. Therefore, according to Newton's second law of motion, the dynamic behaviour of the FPSE can be modelled as follows:

$$
\begin{gathered}
M_{p} \ddot{y}+b(\dot{y}-\dot{x})+b_{p} \dot{y}+K_{p} y=-\left(P-P_{0}\right)\left(A-A_{r}\right), \\
M_{d} \ddot{x}+b(\dot{x}-\dot{y})+b_{d} \dot{x}+K_{d} x=-\left(P-P_{0}\right) A_{r} .
\end{gathered}
$$

Obviously, the dynamics of the FPSE was described by the two coupled secondorder differential equations. Consequently, the FPSE was a fourth-order dynamic system with gas pressure as input excitation. Using ideal gas law, a nonlinear relationship for the instantaneous pressure of the gaseous working fluid inside the engine chamber can be acquired as:

$$
\hat{P}=M R\left(\frac{V_{K}}{T_{C}}+\frac{V_{H}}{T_{H}}\right)^{-1} .
$$

It is important to note that as regenerator was not considered in the free piston engine, the corresponding volume was ignored in Eq. (3). The nonlinearity presented in Eq. (3) is due to the changes in the volumes of expansion and compression spaces. The volumes of expansion and compression spaces are themselves functions of pistons positions ( $x$ and $y$ ) and can be expressed as (see Fig. 1)

$$
\begin{gathered}
V_{h}=V_{h o}-A x, \\
V_{k}=V_{k o}+\left(A-A_{r}\right) x-\left(A-A_{r}\right) y .
\end{gathered}
$$

In order to achieve a linear dynamic system, the nonlinear pressure equation (presented by Eq. (3)) was first linearized around an equilibrium state. For convenience, it was done around the initial volumes $V_{k o}$ and $V_{h o}$, which coincides with the positions $x=0$ and $y=0$. Thus, the linearization of Eq. (3) results in the following linear pressure equation:

$$
P \approx P_{0}+\left.\frac{\partial \hat{P}}{\partial V_{h}}\right|_{V_{h}=V_{h 0}} ^{V_{k}=V_{k 0}}\left(V_{h}-V_{h 0}\right)+\left.\frac{\partial \hat{P}}{\partial V_{k}}\right|_{V_{h}=V_{h 0}} ^{V_{k}=V_{k 0}}\left(V_{k}-V_{k 0}\right)
$$




$$
\begin{gathered}
P-P_{0}=\left(C_{1} A-C_{2} A+C_{2} A_{r}\right) x+C_{2}\left(A-A_{r}\right) y \\
C_{(1,2)}=M R\left(\frac{V_{h 0}}{T_{H}}+\frac{V_{k 0}}{T_{C}}\right)^{-2}\left(\frac{1}{T_{(C, K)}}\right)
\end{gathered}
$$

Now we can make the Laplace transforms of Eqs. (1), (2), and (3) and after simple algebraic manipulation get the final form of our dynamic model:

$$
\begin{gathered}
s^{2} X=-\frac{\left(b+b_{d}\right)}{M_{d}} s X-\frac{K_{d}}{M_{d}} X+\frac{b}{M_{d}} s Y-\frac{A_{r}}{M_{d}}\left(P-P_{0}\right) \\
s^{2} Y=-\frac{\left(b+b_{p}\right)}{M_{p}} s Y-\frac{K_{p}}{M_{p}} Y+\frac{b}{M_{p}} s X-\frac{\left(A-A_{r}\right)}{M_{p}}\left(P-P_{0}\right) \\
P-P_{0}=\left(C_{1} A-C_{2} A+C_{2} A_{r}\right) X+C_{2}\left(A-A_{r}\right) Y
\end{gathered}
$$

The above linear model can be further presented in the state space form:

$$
\dot{x}_{s}=A_{s} x_{s}, \quad x_{s}(0)=0
$$

where $x_{s}=[x: \dot{x}: y \vdots \dot{y}]$ is the model state vector,

$$
\begin{aligned}
& {\left[\begin{array}{c}
\dot{x} \\
\ddot{x} \\
\dot{y} \\
\ddot{y}
\end{array}\right]=} \\
& {\left[\begin{array}{cccc}
\frac{-K_{d}}{M_{d}}-\frac{A_{r}}{M_{d}}\left(C_{1} A-C_{2}\left(A-A_{r}\right)\right) & \frac{-\left(b_{d}+b\right)}{M_{d}} & \frac{A_{r}}{M_{d}} C_{2}\left(A-A_{r}\right) & \frac{b}{M_{d}} \\
0 & 0 & 0 & 1 \\
\frac{A-A_{r}}{M_{p}}\left(C_{1} A-C_{2}\left(A-A_{r}\right)\right) & \frac{b}{M_{p}} & \frac{-K_{p}}{M_{p}}+\frac{A-A_{r}}{M_{p}} C_{2}\left(A-A_{r}\right) & \frac{-\left(b_{p}+b\right)}{M_{p}}
\end{array}\right]\left[\begin{array}{l}
x \\
\dot{x} \\
y \\
\dot{y}
\end{array}\right]}
\end{aligned}
$$

From the linear dynamical systems theory we now [1] that the dynamic behaviour of the above system is completely characterized by eigenvalues of matrix $A_{s}$, i.e. the roots of its characteristic equation:

$$
\operatorname{det}\left(\lambda I-A_{s}\right)=\lambda^{4}+d_{1} \lambda^{3}+d_{2} \lambda^{2}+d_{3} \lambda+d_{4}=w_{A_{s}}^{4}(\lambda)=0
$$

Where $d_{i}$ are functions of the engine design parameters such as $C_{1}, C_{2}, M_{p}, M_{d}$, $K_{p}, K_{d}, A_{r}$ and $A$ which can be derived as follow:

$$
d_{1}=\left(\frac{b_{d}+b}{M_{d}}\right)+\left(\frac{b_{p}+b}{M_{p}}\right)
$$




$$
\begin{aligned}
d_{2}= & \left(\frac{b_{d}+b}{M_{d}}\right)\left(\frac{b_{p}+b}{M_{p}}\right)-\left(\frac{b^{2}}{M_{p} M_{d}}+\frac{K_{p}}{M_{p}}\right)+ \\
& \left(\frac{\left(A-A_{r}\right)}{M_{p}} C_{2}\left(A-A_{r}\right)-\frac{K_{d}}{M_{d}}\right)-\left(\frac{A_{r}}{M_{d}}\left(C_{1} A-C_{2} A+C_{2} A_{r}\right)\right) \\
d_{3}= & \left(\frac{b_{d}+b}{M_{d}}\right)\left(\frac{K_{p}}{M_{p}}+\frac{\left(A-A_{r}\right)}{M_{p}} C_{2}\left(A-A_{r}\right)\right)+\left(\frac{A_{r} b}{M_{d} M_{p}} C_{2}\left(A-A_{r}\right)\right)- \\
& \left(\frac{K_{d}}{M_{d}}+\frac{\left(A-A_{r}\right)}{M_{d}} C_{2}\left(A-A_{r}\right)\right)\left(\frac{b_{p}+b}{M_{p}}\right)- \\
& \left(\frac{b\left(A-A_{r}\right)}{M_{d} M_{p}}\left(C_{1} A-C_{2} A+C_{2} A_{r}\right)\right) \\
d_{4}= & \left(\frac{K_{p}}{M_{p}}+\frac{\left(A-A_{r}\right)}{M_{p}} C_{2}\left(A-A_{r}\right)\right)\left(\frac{K_{d}}{M_{d}}+\frac{\left(A-A_{r}\right)}{M_{d}} C_{2}\left(A-A_{r}\right)\right)+ \\
& \left(\frac{\left(A-A_{r}\right) A_{r}}{M_{d} M_{p}}\left(C_{1} A-C_{2} A+C_{2} A_{r}\right)\right)
\end{aligned}
$$

Based on the mentioned approach, a design procedure can be devised to design and study the FPSE. Indeed, the values of the four unknown design variables of the FPSE, such as the mass and spring stiffness of power and displacer pistons, were achieved by equating the coefficients of the obtained objective function with those of the characteristic polynomial $w_{A_{s}}^{4}(\lambda)$ in Eq. (14). Thus, by solving the four obtained new equations, the four unknown design parameters will be acquired. In the sequel, on the basis of the acquired values of design parameters and using Eqs. (1) and (2), the motions of power and displacer pistons will be studied.

\section{Analysis of a FPSE using roots loci}

In this section, dynamic behaviour of a FPSE is investigated using root locus technique. As a prototype FPSE, the SUTech-SR-1 developed at Shiraz University of Technology [21] was considered in this work. The specifications of the mentioned FPSE were given in Table 1. First, the root locus analysis of the prototype engine was implemented considering each of the engine design parameters $\left(T_{H}, T_{C}, M_{p}\right.$, $M_{d}, M, K_{p}, K_{d}$ ) as an objective variable (in Eqs. (15) to (18)). Consequently, the roots loci can be easily plotted for each value of the objective variable which leads to a new place of characteristic roots on the s-plane based on Eq. (14). Accordingly, the combination of the roots places corresponding to each value of the objective variable form the resultant root locus plots. 
Values of design parameters of the prototype FPSE (SUTech-SR-1)

\begin{tabular}{|c|l||c|l|}
\hline Parameter & \multicolumn{1}{|c||}{ Value } & Parameter & \multicolumn{1}{|c|}{ Value } \\
\hline$A$ & $0.00096\left(\mathrm{~m}^{2}\right)$ & $M_{p}$ & $0.507(\mathrm{~kg})$ \\
\hline$P_{0}$ & $100(\mathrm{kPa})$ & $R$ & $287\left(\mathrm{~J} \mathrm{~kg}^{-1} \mathrm{~K}^{-1}\right)$ \\
\hline$M$ & $4.58 \cdot 10^{-5}(\mathrm{~kg})$ & $T_{H}$ & $519(\mathrm{~K})$ \\
\hline$K_{d}$ & $202\left(\mathrm{Nm}^{-1}\right)$ & $T_{C}$ & $333(\mathrm{~K})$ \\
\hline$K_{p}$ & $598\left(\mathrm{Nm}^{-1}\right)$ & $V_{h_{0}}$ & $1.91 \cdot 10^{-5}\left(\mathrm{~m}^{3}\right)$ \\
\hline$M_{d}$ & $0.079(\mathrm{~kg})$ & $V_{k_{0}}$ & $1.92 \cdot 10^{-5}\left(\mathrm{~m}^{3}\right)$ \\
\hline
\end{tabular}

\subsection{Effects of gas temperature on the FPSE dynamics using root locus method}

The first important parameter affecting the instability of the regulator system (i.e., the FPSE) was the gas temperature. Fig. 4 depicts the root-locus plot for variation of the gas temperature in the expansion space ranging from $273 \mathrm{~K}$ to $1500 \mathrm{~K}$. It can be seen that, by increasing the hot gas temperature, the dominant closed-loop poles of the engine system starts to move towards the right-hand side of the s-plane (RHP). This means that the engine system tends to become more unstable as the hot gas temperature is increased. As a result, a more output power can be expected. In contrast, by increasing the value of cold gas temperature from $273 \mathrm{~K}$ to $800 \mathrm{~K}$, the dominant poles move to the left half of the s-plane as shown in Fig. 5 and consequently, the engine will stop working.

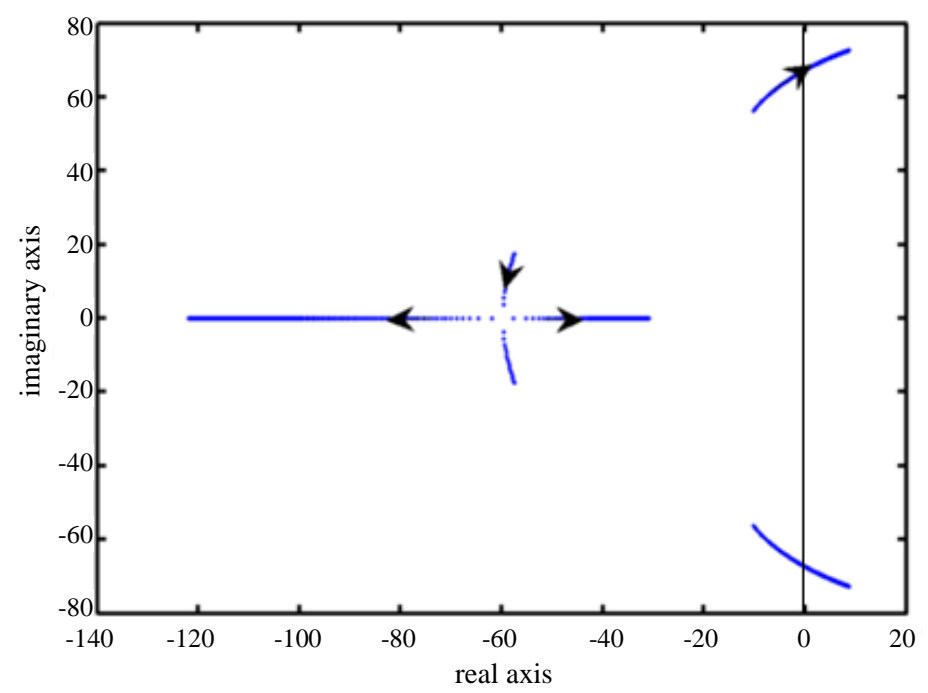

Fig. 4. Root locus diagram for varying values of the hot gas temperature $T_{H}$ within the range $273 \mathrm{~K}-1500 \mathrm{~K}$ 


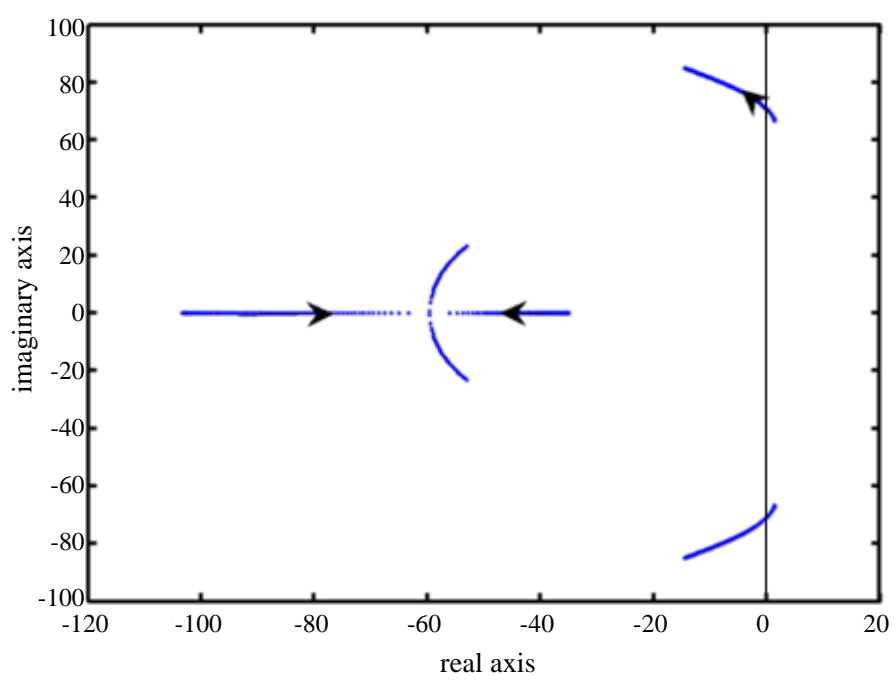

Fig. 5. Root locus diagram for varying values of the cold gas temperature $T_{C}$ within the range $273 \mathrm{~K}-800 \mathrm{~K}$

\subsection{Effects of springs stiffness on the FPSE dynamics using root locus method}

Another important parameter affecting the performance and instability of the FPSE is the stiffness of the springs of the power and displacer pistons. These latest issues are investigated in this subsection. The root-locus plot for varying values of the power piston stiffness is demonstrated in Fig. 6. Obviously, by increasing the

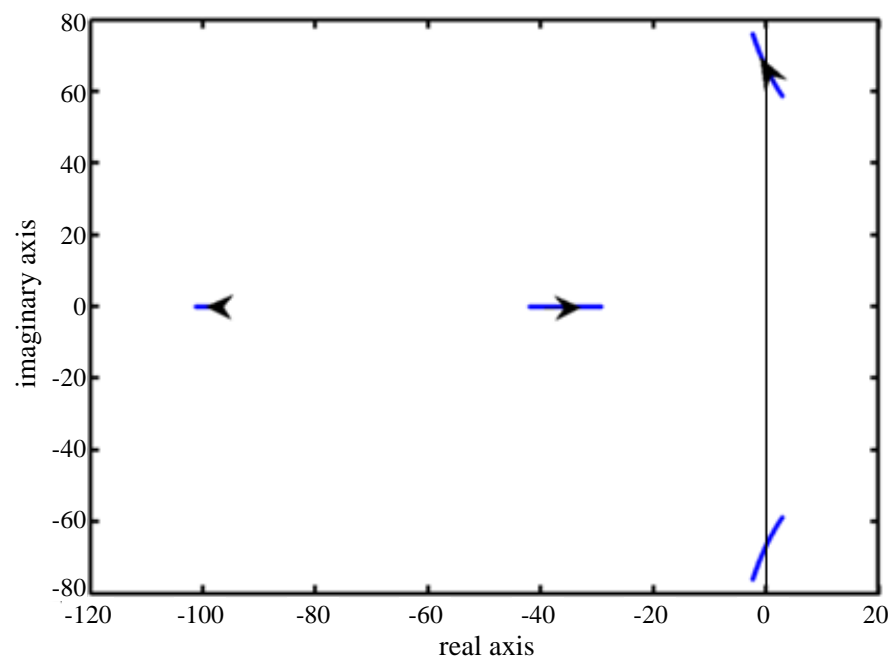

Fig. 6. Root-locus diagram for varying values of the spring stiffness of the power piston within the range $0 \mathrm{~N} / \mathrm{m}-2000 \mathrm{~N} / \mathrm{m}$ 
value of the stiffness of the power piston (from 0 to $2000(\mathrm{~N} / \mathrm{m})$ ), the dominant closed-loop poles of the dynamic system gradually move to the left half of the splane and, as a result, the engine will be shut down. Also, by increasing the amount of spring stiffness of the displacer piston in the range 0 to $2000(\mathrm{~N} / \mathrm{m})$, a more unstable dynamics can be obtained initially. However, increasing the displacer stiffness beyond a distinct level causes the dominant poles to be moved in the opposite direction, as shown in Fig. 7. Consequently, there exists an optimum point at which a maximum output power can be picked up (see Fig. 7).

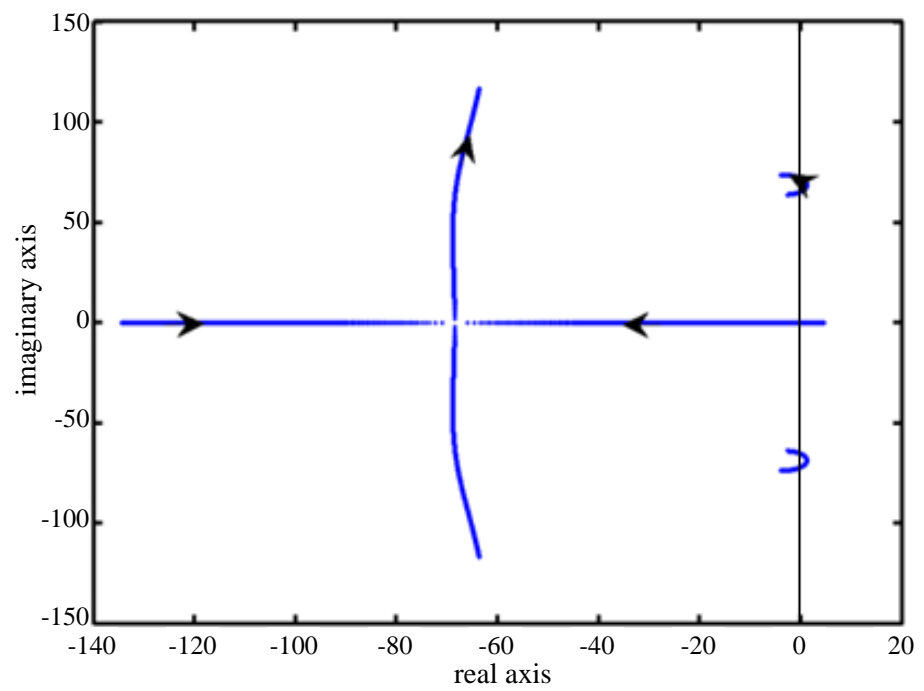

Fig. 7. Root-locus diagram for varying values of spring stiffness of the displacer piston within the range $0 \mathrm{~N} / \mathrm{m}-2000 \mathrm{~N} / \mathrm{m}$

\subsection{Effect of piston mass on the FPSE dynamics using root locus method}

According to Fig. 8, it can be inferred that by increasing the mass of the power piston ranging from $0.005 \mathrm{~kg}$ to $2 \mathrm{~kg}$, the dominant closed-loop poles enter the right half of the s-plane and the dynamic system become more unstable. However, the system frequency is decreased considerably as the imaginary component of the closed-loop poles is diminished. Moreover, increasing the mass of displacer piston from 0.005 to $0.5 \mathrm{~kg}$ has a negative effect on the instability of the engine system (Fig. 9).

\subsection{Effects of gas mass on the FPSE dynamics using root locus method}

The gas mass inside the engine cylinder plays a crucial role in the performance of FPSEs. As discussed earlier, the gas mass was expressed as the sum of gas masses in the expansion and compression spaces as well as the gas mass inside 


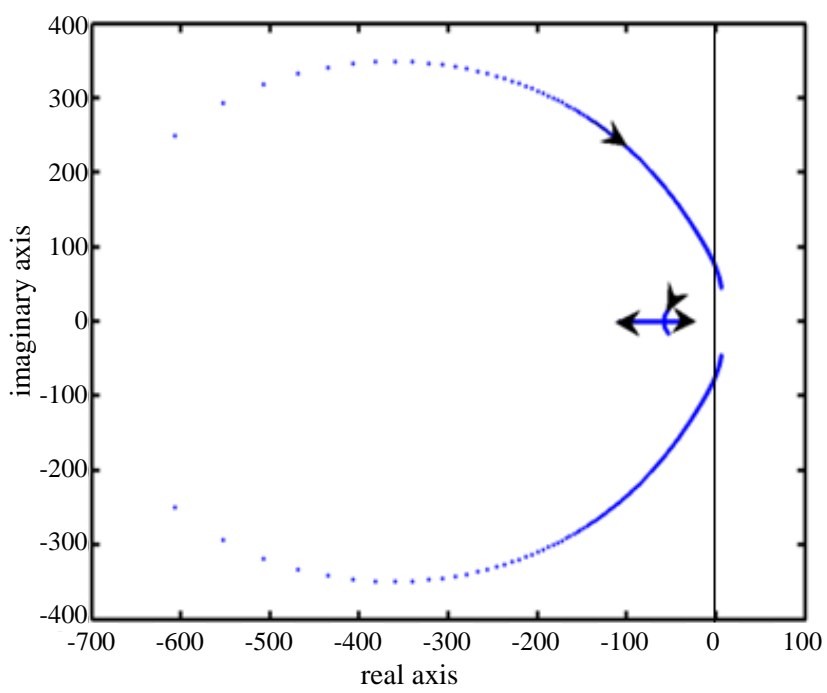

Fig. 8. Root-locus diagram for varying values of the power piston mass within the range $0.005 \mathrm{~kg}-2 \mathrm{~kg}$

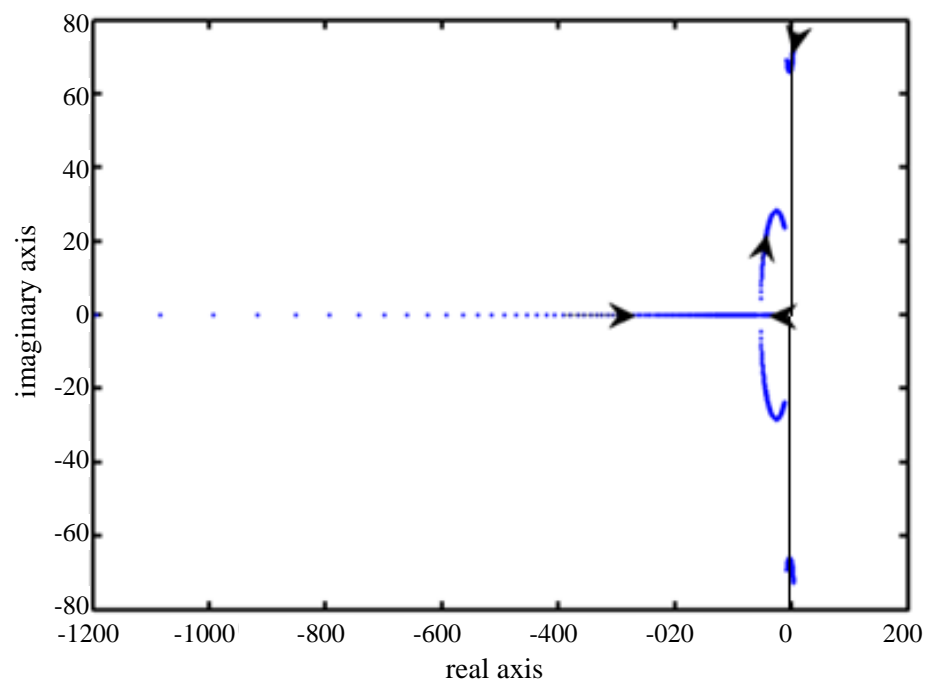

Fig. 9. Root-locus diagram for varying values of the displacer piston mass within the range $0.005 \mathrm{~kg}-0.5 \mathrm{~kg}$

the regenerator space. Fig. 10 shows that by increasing the value of gas mass from 0.005 to $0.5 \mathrm{~kg}$, the dominant closed-loop poles enter the right half of the s-plane and eventually, the engine system becomes more unstable. In addition, this change significantly increases the operating frequency of the FPSE system. 


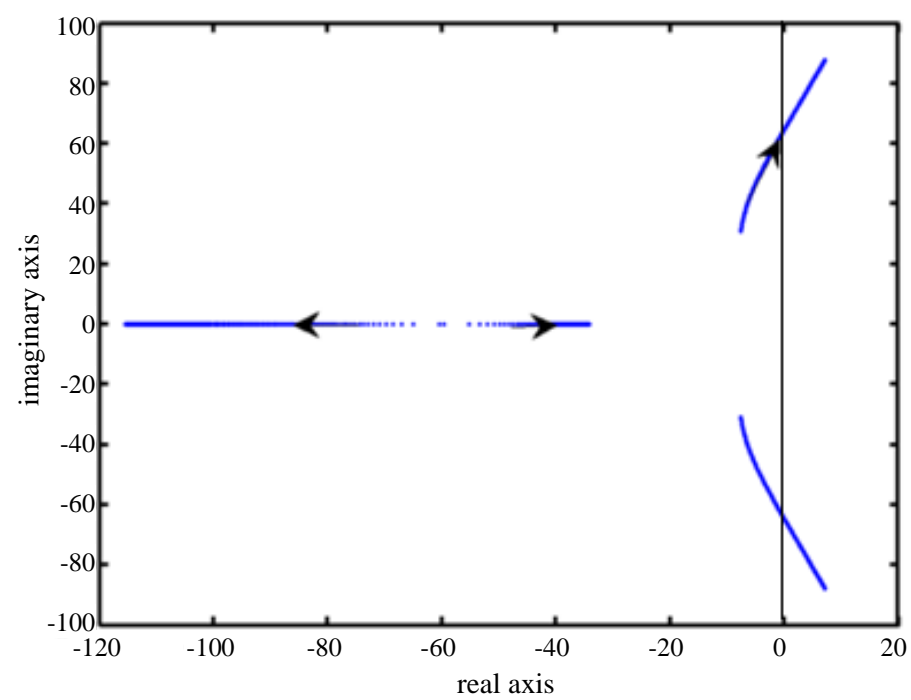

Fig. 10. Root locus diagram for increasing value of the gas mass within the range $0.005 \mathrm{~kg}-0.5 \mathrm{~kg}$

Till now, the performance of a FPSE, namely SUTech-SR-1, was investigated using a control-based design scheme. However, a question may arise about the validity of the proposed mathematical scheme. In the following sections, it was attempted to respond this important question.

\section{Validity of the presented control-based analytical approach}

In this section, it was strived to show the validity of the control-based analysis of the free piston hot-air engines by comparing the engine power estimated by the proposed control-based mathematical approach to those of an experimental engine and the Beale number prediction. In the following subsections, first a prototype engine, namely SUTech-SR-1, was experimented so as to find the engine work power. Then, the output power of the free piston engine was calculated based on the operating frequency using the presented root-locus analysis. Finally, the well-known Beale number approach was used to predict the engine power.

\subsection{Measured output power of the experimental engine}

As mentioned earlier, in this work the prototype FPSE, namely SUTech-SR1 (see Fig. 11) along with its corresponding characteristics, were considered throughout the paper. The values of engine design parameters as well as the operating temperatures were previously given in Table 1 . This engine has been designed based on the target frequency of $70 \mathrm{rad} / \mathrm{s}$ at the Shiraz University of Technology. The output power of the prototype engine was measured as $2.7 \mathrm{~W}$ at frequency of $67.9 \mathrm{rad} / \mathrm{s}$. More details on the experimental work and the measurement technique can be found in [21]. 


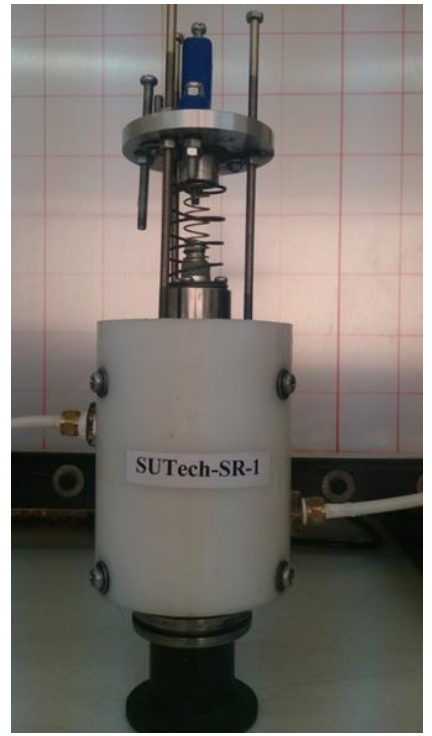

Fig. 11. The prototype free-piston Stirling engine (SUTech-SR-1)

\subsection{Estimation of the output power using root locus technique}

The operating frequency of an FPSE is an important design parameter that considerably affects the performance of such thermal converters. As mentioned earlier, the operating frequency of the engine system could be found based on the imaginary component of the dominant closed-loop poles of the dynamic system. In this section, an objective frequency of about $70 \mathrm{rad} / \mathrm{s}$ was first considered in the design process. Accordingly, the positions of the desired closed loop poles on the s-plane were selected such that marginal stability was found (see Table 2). Consequently, an objective polynomial function with the roots given in Table 2 could be formed. Then, the values of the four unknown design variables of the FPSE, such as the mass and spring stiffness of power and displacer pistons, were acquired by equating the coefficients of the obtained objective function with those of the characteristic polynomial $w_{A_{s}}^{4}(\lambda)$ in Eq. (14). Thus, by solving the four obtained new equations, the four unknown design parameters could be obtained (see Table 3). At the end of the day, based on the obtained values of design parameters and using Eqs. (1) and (2), the motions of power and displacer pistons could be simulated via the central finite difference method as previously discussed in [14]. Afterwards, the simulated motions of power and displacer pistons were further employed to investigate the variations of gas pressure (see Eq. 3) as well as the gas volume inside the engine (see Eqs. (4) and (5)). Accordingly, the generated work could be calculated through the corresponding P-V diagram. Finally, the engine power was found as $2.89 \mathrm{~W}$ by multiplying the desired frequency by the calculated work. 
Values of the closed-loop poles considering the desired frequency of $70 \mathrm{rad} / \mathrm{s}$

\begin{tabular}{|c|c|c|c|}
\hline \multicolumn{2}{|c|}{$\begin{array}{c}\text { Dominant } \\
\text { poles }\end{array}$} & \multicolumn{2}{c|}{$\begin{array}{c}\text { Non-dominant } \\
\text { poles }\end{array}$} \\
\hline $70 \mathrm{j}$ & $-70 \mathrm{j}$ & -35 & -100 \\
\hline
\end{tabular}

Table 3 .

Values of the design parameters based on the desired frequency of $70 \mathrm{rad} / \mathrm{s}$

\begin{tabular}{|c|c|c|c|c|}
\hline $\begin{array}{c}\text { Frequency } \\
(\mathrm{rad} / \mathrm{s})\end{array}$ & $\begin{array}{c}M_{p} \\
(\mathrm{~kg})\end{array}$ & $\begin{array}{c}M_{d} \\
(\mathrm{~kg})\end{array}$ & $\begin{array}{c}K_{p} \\
(\mathrm{~m} / \mathrm{m})\end{array}$ & $\begin{array}{c}K_{d} \\
(\mathrm{~N} / \mathrm{m})\end{array}$ \\
\hline 70 & 0.507 & 0.079 & 598 & 202 \\
\hline
\end{tabular}

\subsection{Prediction of the output power using the well-defined Beale number approach}

Beale [1] carried out extensive researches on the Stirling engines experimentally. These researches resulted in a practical design formula for the Stirling engines. This method is known as the so-called Beale number $(B N)$ today. Beale number approach is an important methodology to estimate the output power of various types of Stirling engines. According to the Beale formula, the output power of Stirling engines can be estimated as [1]:

$$
\text { Power }=10 B N f V_{p} P_{m}
$$

where $P_{m}$ is the mean pressure (bar), $V_{P}$ is the swept volume of the power piston $\left(\mathrm{m}^{3}\right), f$ is engine speed or frequency ( $\left.\mathrm{rad} / \mathrm{s}\right)$, and $B N$ is the so-called Beale number. There are many ways to reach the Beale number one of which is known as the Walker curve [1]. Walker presented the Beale number as a function of the source temperature $\left(T_{H}\right)$. It is clearly demonstrated in Fig. 12 and is considered in many

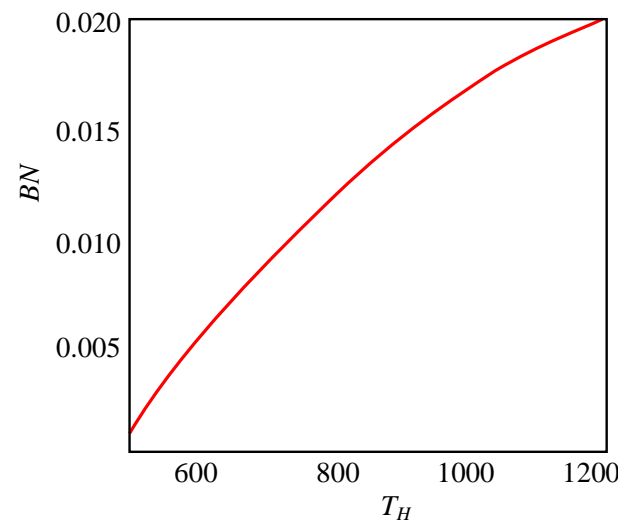

Fig. 12. Beale number as a function of heating source temperature [1] 
practical designs of the Stirling engines. However, this curve is usually useable for the source temperatures above $475 \mathrm{~K}$.

One should keep in mind that the mean pressure $P_{m}$ in Eq. (19) is in fact the average value of the gas pressure in Eq. (11) over one cycle. Based on the Schmidt's theory, the assumption of sinusoidal motions of power and displacer pistons are reasonable [14]. Thus, by considering this assumption in Eq. (11) the mean pressure $\left(P_{m}\right)$ can be computed. Consequently, at frequency of $70 \mathrm{rad} / \mathrm{s}$ the engine power was found as $2.82 \mathrm{~W}$ using the Beale number approach.

\subsection{A brief summary}

Based on the presented investigation on the output power of the considered FPSE, it is obvious that the results obtained from the proposed control based analysis are in a good agreement with those of the Beale number approach and the experiment. Consequently, validity of the proposed control-based design technique is affirmed to some extent. Table 4 summarizes the obtained comparative output powers

Table 4.

Comparison of the experimental output power with those of the Beale number and root locus techniques

\begin{tabular}{|c|c|c|}
\hline $\begin{array}{c}\text { Experiment } \\
\text { (W) }\end{array}$ & $\begin{array}{c}\text { Root lotus } \\
\text { (W) }\end{array}$ & $\begin{array}{c}\text { Beale number } \\
\text { (W) }\end{array}$ \\
\hline 2.7 & 2.89 & 2.82 \\
\hline
\end{tabular}

of the engine using three methods. It is interesting to note that the estimated power by the control-based analysis is very close to those estimated by Beale number approach. Beside, inspection of the phase portrait (Fig. 13) shows that the simulation results (root locus) are in a good agreement with the experiment outcomes through

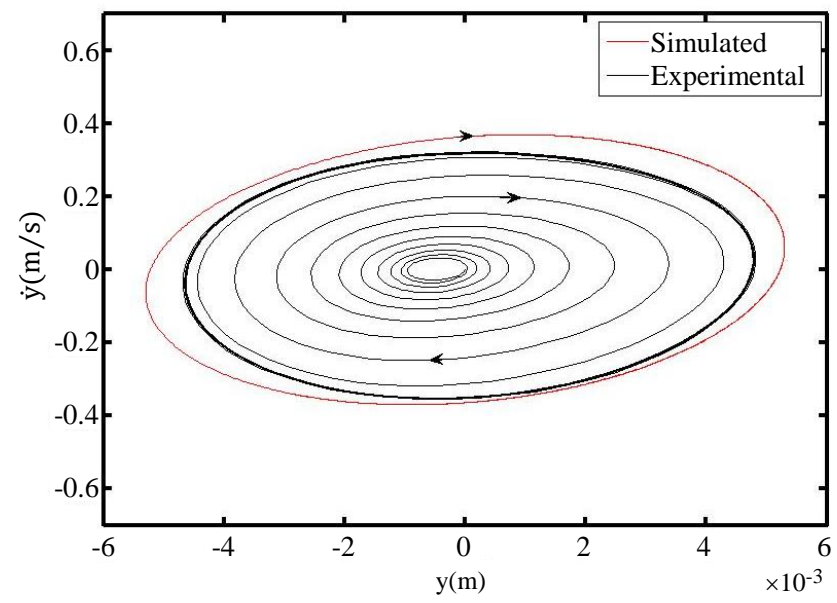

Fig. 13. Simulated and experimental phase trajectories of the power piston 
which more evidence regarding the validity of the proposed mathematical scheme was found. One should keep in mind that the paper was focused on linear analysis of FPSE. Although, nonlinear analysis of FPSE is of practical importance, it is beyond the scope of this work. Consequently, the next research will be directed toward an extensive investigation on Lyapunov analysis and nonlinear modeling of FPSE as well. The following section attempts to present a comparison between the Beale number approach and the root locus analysis of the free piston Stirling engine with more details.

\section{A comparative study between the root locus and Beale number techniques}

In this section, the Beale number and root locus design techniques are compared taking into account seven target frequencies such as $55 \mathrm{rad} / \mathrm{s}, 60 \mathrm{rad} / \mathrm{s}, 65 \mathrm{rad} / \mathrm{s}$, $70 \mathrm{rad} / \mathrm{s}, 75 \mathrm{rad} / \mathrm{s}, 80 \mathrm{rad} / \mathrm{s}$, and $85 \mathrm{rad} / \mathrm{s}$. Table $5 \mathrm{summarizes} \mathrm{the} \mathrm{locations} \mathrm{of} \mathrm{the}$ selected poles of the engine corresponding to each frequency. As can be seen in this table, in each case, two dominant poles were selected on the imaginary axis of the s-plane to provide the desired frequency. Moreover, the non-dominant poles were chosen far enough to the left side of the s-plane so that their effect on the system response becomes insignificant. In addition, the imaginary components of the non-dominant roots were eliminated to avoid any possible perturbations in the motions of the power and displacer pistons.

Table 5 .

Values of the closed-loop poles on the s-plane

\begin{tabular}{|c|c|c|c|c|}
\hline $\begin{array}{c}\text { Case } \\
\text { number }\end{array}$ & \multicolumn{2}{|c|}{$\begin{array}{c}\text { Dominant } \\
\text { poles }\end{array}$} & \multicolumn{2}{c|}{$\begin{array}{c}\text { Non-dominant } \\
\text { poles }\end{array}$} \\
\hline 1 & $55 \mathrm{j}$ & $-55 \mathrm{j}$ & -45 & -60 \\
\hline 2 & $60 \mathrm{j}$ & $-60 \mathrm{j}$ & -30 & -105 \\
\hline 3 & $65 \mathrm{j}$ & $-65 \mathrm{j}$ & -55 & -60 \\
\hline 4 & $70 \mathrm{j}$ & $-70 \mathrm{j}$ & -35 & -100 \\
\hline 5 & $75 \mathrm{j}$ & $-75 \mathrm{j}$ & -50 & -70 \\
\hline 6 & $80 \mathrm{j}$ & $-80 \mathrm{j}$ & -45 & -70 \\
\hline 7 & $85 \mathrm{j}$ & $-85 \mathrm{j}$ & -60 & -75 \\
\hline
\end{tabular}

Thus, based on the desired frequencies and the corresponding closed-loop poles, mass $\left(M_{p}, M_{d}\right)$ of the power and displacer pistons and their spring stiffness $\left(K_{d}, K_{p}\right)$ were acquired for each case (see Table 6) using the methodology described in subsection 5.1.

Next, the output power was found corresponding to each frequency via the root locus and Beale number approaches described in subsection 5.1 and 5.2, respectively. The comparative results of the predicted powers by each technique 
Values of the design parameters based on the desired frequency

Table 6.

\begin{tabular}{|c|c|c|c|c|}
\hline $\begin{array}{c}\text { Frequency } \\
(\mathrm{rad} / \mathrm{s})\end{array}$ & $\begin{array}{c}M_{p} \\
(\mathrm{~kg})\end{array}$ & $\begin{array}{c}M_{d} \\
(\mathrm{~kg})\end{array}$ & $\begin{array}{c}K_{p} \\
(\mathrm{~m} / \mathrm{m})\end{array}$ & $\begin{array}{c}K_{d} \\
(\mathrm{~N} / \mathrm{m})\end{array}$ \\
\hline 55 & 0.534 & 0.091 & 483 & 166 \\
\hline 60 & 0.523 & 0.087 & 526 & 179 \\
\hline 65 & 0.518 & 0.084 & 552 & 191 \\
\hline 70 & 0.507 & 0.079 & 598 & 202 \\
\hline 75 & 0.496 & 0.077 & 628 & 213 \\
\hline 80 & 0.481 & 0.073 & 669 & 220 \\
\hline 85 & 0.473 & 0.066 & 711 & 224 \\
\hline
\end{tabular}

Comparative output powers of the engine

Table 7.

\begin{tabular}{|c|c|c|}
\hline $\begin{array}{c}\text { Frequency } \\
(\mathrm{rad} / \mathrm{s})\end{array}$ & $\begin{array}{c}\text { Proposed } \\
\text { method }(\mathrm{W})\end{array}$ & $\begin{array}{c}\text { Beale number } \\
\text { concept }(\mathrm{W})\end{array}$ \\
\hline 55 & 2.31 & 2.22 \\
\hline 60 & 2.43 & 2.32 \\
\hline 65 & 2.61 & 2.61 \\
\hline 70 & 2.89 & 2.82 \\
\hline 75 & 3.1 & 3.12 \\
\hline 80 & 3.18 & 3.24 \\
\hline 85 & 3.51 & 3.43 \\
\hline
\end{tabular}

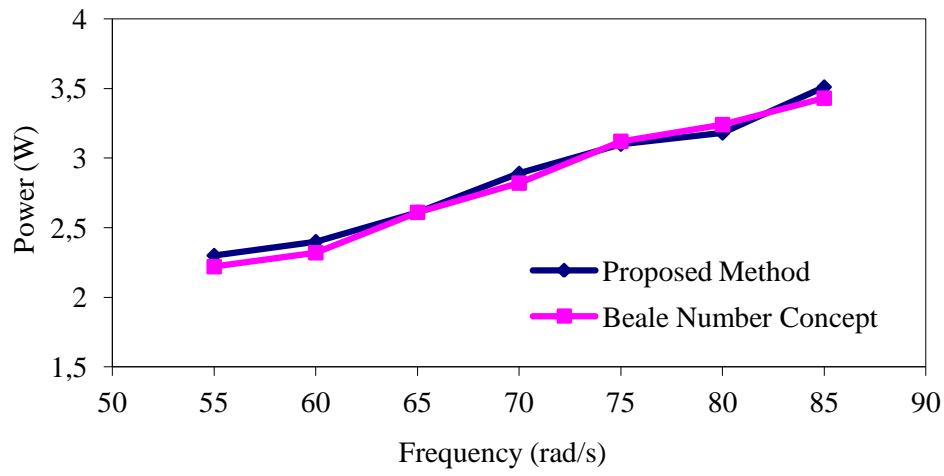

Fig. 14. Calculated output power versus desired frequency based on Beale formula and proposed

were reported in Table 7 and then were plotted in Fig. 14. It can be clearly seen that the results of the proposed control-based analysis are in a good agreement with those obtained from the conventional Beale formula.

At this moment, a question may arise about the ability of the proposed controlbased analysis to predict the Beale number. Thus, the obtained results presented 


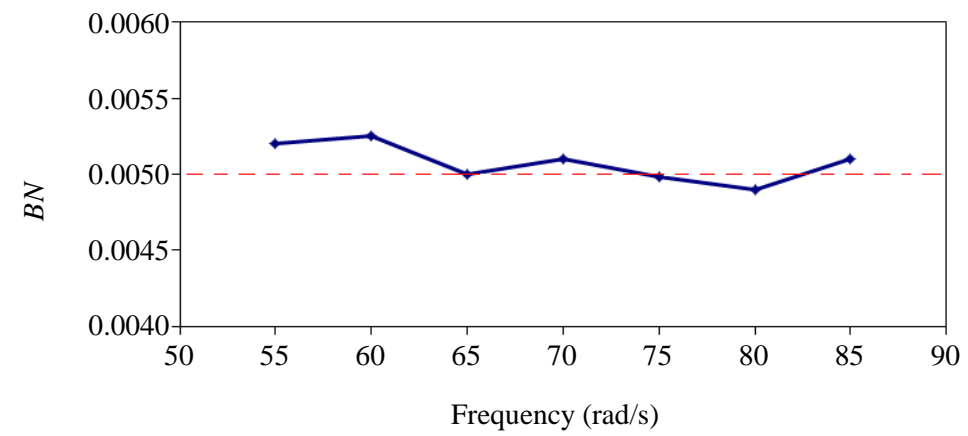

Fig. 15. Calculated Beale number from proposed method

in Table 7 were employed to calculate the Beale number for each frequency. As it is represented in Fig. 15, the calculated values of $B N$ based on the control-based analysis (see solid lines) are close to that of the Walker curve (see dash line) considering the heat source temperature of $600 \mathrm{~K}$.

\section{Conclusion}

In this research, pole placement-based analysis of FPSEs was introduced as an alternative to the conventional Beale number approach. It was represented that the root locus technique enabled one to predict the engine performance at different operating conditions and based on different values of design parameters. Although the fully thermodynamic design approach as well as the well-known Beale formula have been used extensively by researchers to design the FPSEs, it was shown that the proposed design approach can be another reliable technique for designing such Stirling engines. In this work, the proposed design method was established based on an appropriate selection of the dominant and non-dominant closed-loop poles such that a desired frequency was acquired. It is important to note that the dominant poles should be chosen in such a way that the dynamic system becomes periodical or even unstable in order to generate energy. In this approach, the output power could also be computed through the simultaneous application of the dynamic and thermodynamic equations in the state-space. Unlike the previous reports in which the values of design variables such as mass and spring stiffness for both power and displacer pistons were obtaining by trial and error schemes, a very systematic way to design the FPSEs was proposed in this article. Furthermore, the validity of the proposed control-based design technique was evaluated through a comparative study among the proposed method, the conventional Beale number, and the experimental data. The outcomes of this work clearly revealed the effectiveness of the proposed design technique of FPSEs compared to the conventional approaches such as Beale number. 


\title{
Acknowledgements
}

The authors wish to acknowledge the Shiraz University of Technology and Iran's National Elites Foundation for providing research facilities and funding. A special thank is dedicated to the paper reviewers for their helpful and constructive comments.

\author{
Manuscript received by Editorial Board, November 20, 2016; \\ final version, August 25, 2017.
}

\section{References}

[1] G. Walker. Stirling Engines. Clarendon Press, Oxford, 1980.

[2] A.R. Tavakolpour-Saleh, SH. Zare, and H. Badjian. Multi-objective optimization of Stirling heat engine using gray wolf optimization algorithm. International Journal of Engineering -Transactions C: Aspects, 30(6):321-329, 2017. doi:10.5829/idosi.ije.2017.30.06c.00.

[3] H. Jokar and A.R. Tavakolpour-Saleh. A novel solar-powered active low temperature differential Stirling pump. Renewable Energy, 81:319-337, 2015. doi:10.1016/j.renene.2015.03.041.

[4] K. Wang, S.R. Sanders, S. Dubey, F.H. Choo, and F. Duan. Stirling cycle engines for recovering low and moderate temperature heat: A review. Renewable and Sustainable Energy Reviews, 62:89-108, 2016. doi:10.1016/j.rser.2016.04.031.

[5] G. Walker and J.R. Senft. Free Piston Stirling Engines. Springer-Verlag Berlin Heidelberg, 1985.

[6] A.R. Tavakolpour, A. Zomorodian, and A.A. Golneshan. Simulation, construction and testing of a two-cylinder solar Stirling engine powered by a flat-plate solar collector without regenerator. Renewable Energy, 33(1):77-87, 2008. doi:10.1016/j.renene.2007.03.004.

[7] C.-H. Cheng, H.-S. Yang, and L. Keong. Theoretical and experimental study of a 300-W beta-type Stirling engine. Energy, 59:590-599, 2013. doi:10.1016/j.energy.2013.06.060.

[8] I. Tlili and S.A. Musmar. Thermodynamic evaluation of a second order simulation for Yoke Ross Stirling engine. Energy conversion and management, 68:149-160, 2013. doi:10.1016/j.enconman.2013.01.005.

[9] H. Hachem, R. Gheith, F. Aloui, and S.B. Nasrallah. Numerical characterization of a $\gamma$-stirling engine considering losses and interaction between functioning parameters. Energy Conversion and Management, 96:532-543, 2015. doi:10.1016/j.enconman.2015.02.065.

[10] W.T. Beale. Free piston Stirling engines - some model tests and simulations. In International Automotive Engineering Congress, Detroit, January 13-17 1969. SAE Technical Paper No. 690230.

[11] SH. Zare, A.R. Tavakolpour-Saleh, and O. Aghajanzadeh. An investigation on the effects of gas pressure drop in heat exchangers on dynamics of a free piston Stirling engine. International Journal of Engineering - Transactions B: Applications, 30(2):150-160, 2017. doi:10.5829/idosi.ije.2017.30.02b.00.

[12] A.R. Tavakolpour-Saleh, SH. Zare, and H. Bahreman. A novel active free piston Stirling engine: Modeling, development, and experiment. Applied Energy, 199:400-415, 2017. doi:10.1016/j.apenergy.2017.05.059.

[13] F. Formosa. Coupled thermodynamic-dynamic semi-analytical model of free piston Stirling engines. Energy Conversion and Management, 52(5):2098-2109, 2011. doi:10.1016/j.enconman.2010.12.014.

[14] SH. Zare and A.R. Tavakolpour-Saleh. Frequency-based design of a free piston Stirling engine using genetic algorithm. Energy, 109:466-480, 2016. doi:10.1016/j.energy.2016.04.119. 
[15] H. Karabulut. Dynamic analysis of a free piston Stirling engine working with closed and open thermodynamic cycles. Renewable Energy, 36(6):1704-1709, 2011. doi:10.1016/j.renene.2010.12.006.

[16] S. Kwankaomeng, B. Silpsakoolsook, and P. Savangvong. Investigation on stability and performance of a free-piston Stirling engine. Energy Procedia, 52:598-609, 2014. doi:10.1016/j.egypro.2014.07.115.

[17] S. Kwankaomeng, B. Silpsakoolsook, and T. Kaweemong-Kolrat. Experimental investigation of an engineering. In International Conference in Agricultural Engineering, Chon-Chan Pattaya Resort, Chonburi, Thailand, 31 March-1 April 2011.

[18] N. Vichaidit, N. Aksornpromrat, and S. Kijswang. Design and construction of free -piston type Stirling engine. Final year project report, Department of Mechanical Engineering, Siam University, 2009.

[19] E.D. Rogdakis, N.A. Bormpilas, and I.K. Koniakos. A thermodynamic study for the optimization of stable operation of free piston Stirling engines. Energy Conversion and Management, 45(4):575-593, 2004. doi:10.1016/S0196-8904(03)00175-4.

[20] J. Boucher, F. Lanzetta, and P. Nika. Optimization of a dual free piston Stirling engine. Applied Thermal Engineering, 27(4):802-811, 2007. doi:10.1016/j.applthermaleng.2006.10.021.

[21] A.R. Tavakolpour-Saleh, SH. Zare, and A. Omidvar. Applying perturbation technique to analysis of a free piston Stirling engine possessing nonlinear springs. Applied Energy, 183:526-541, 2016. doi:10.1016/j.apenergy.2016.09.009. 